\title{
ORGANIZACIÓN Y PROCEDIMIENTO DEL SISTEMA DE JUSTICIA INDÍGENA EN LAS COMUNIDADES DE CHIAPAS
}

\author{
ORGANIZATION AND PROCEDURE OF THE INDIGENOUS JUSTICE SYSTEM \\ IN THE COMMUNITIES OF CHIAPAS
}

\author{
Jesús AlFREDo Galindo Albores \\ Profesor e investigador de la Universidad Autónoma de Chiapas, México \\ galialf@hotmail.com \\ LORENZO LÓPEZ MÉNDEZ \\ Doctor en Derechos Humanos, ex ombudsman de Chiapas \\ lmlorenzo2010@hotmail.com
}

\section{Resumen:}

El sistema de justicia tradicional indígena en México y los mecanismos para las resolución de sus conflictos frecuentemente se tensionan con la normatividad jurídica estatal y los derechos humanos. El presente artículo se refiere a esas situaciones particulares, así como a la organización y funcionamiento del sistema de justicia en las comunidades indígenas de Chiapas, entidad del sur de México, a partir del análisis de los elementos que la soportan: cosmovisión, oralidad y casuística. Una justicia que encuentra en el orden constitucional $y$ en instrumentos internacionales el reconocimiento de los usos y costumbres, para dar paso a un orden normativo no codificado en la regulación y solución de conflictos internos y comunitarios, de manera paralela al sistema jurídico nacional.

Palabras clave: Justicia indígena, usos y costumbres, cosmovisión, casuístico, derechos humanos.

\begin{abstract}
:
The traditional indigenous justice system in Mexico and the mechanisms for the resolution of their conflicts are often stressed by the legal state regulations and the human rights. This article refers to those particular situations, as well as to the organization and functioning of the justice system in the indigenous communities of Chiapas, an entity in southern Mexico, based on the analysis of the elements that support it: worldview, orality and casuistry. A justice that finds in the constitutional order and in international instruments the recognition of the uses and customs, to give way to a normative order not codified in the regulation and solution of internal and community conflicts, in parallel to the national legal system.
\end{abstract}

Keywords: Indigenous justice, uses and customs, worldview, casuistry, human rights.

Sumario: 1. Introducción. 2. Justicia acusatoria adversarial, justicia indígena y cosmovisión. 3. Las autoridades responsables de impartir la justicia indígena. 4. Los Juzgados de Paz y Conciliación Indígena en Chiapas. 5. El procedimiento en la justicia

REJIE Nueva época: Revista Jurídica de Investigación e Innovación Educativa Núm.20, Junio 2019, pp. 89-110 [En línea] http://www.revistas.uma.es/index.php/rejie Recibido: diciembre 2018 Aceptado: abril 2019 
indígena. 6. La oralidad y la casuística, elementos que sustentan el sistema consuetudinario de justicia indígena. 7. Conclusiones. Bibliografía. Recursos en Red.

\section{Introducción.}

Varios de los conflictos de interés jurídico que implican violaciones a derechos humanos en las comunidades indígenas de México derivan de la coexistencia, no siempre pacífica, de un orden jurídico nacional y las costumbres jurídicas de los pueblos indígenas ${ }^{1}$. Esta reflexión inicial marca la pauta de la presente investigación, que analiza los usos y costumbres que dan origen a un derecho consuetudinario en diversas comunidades de Chiapas, entidad del sur de México, a partir de una mejor comprensión de la compleja realidad en que se desarrolla cotidianamente su existencia.

En México existen constitucionalmente dos sistemas de justicia. La justicia indígena, aquella que ha existido ancestralmente hasta nuestros días en pueblos y comunidades, sustentada en un procedimiento, normas no escritas y operadores tradicionales, elegidos por usos y costumbres, reconocida constitucionalmente pero no codificada, que puede presentar variantes de un pueblo indígena a otro. Por otra parte, se encuentra el sistema de justicia nacional, codificada y positivada, que se aplica en procuradurías o similares, juzgados del fuero común y federal, y por ende, goza del reconocimiento pleno del aparato de justicia estatal.

Para entender la esencia normativa de los usos y costumbres, como fundamento de los procedimientos que los pueblos indígenas utilizan para resolver sus conflictos y diferencias, es menester reconocer que existe una lucha permanente en sede interna por parte de los pueblos indígenas por el derecho al ejercicio de su propio derecho. Esta batalla indígena ha encontrado su mejor aliado en los instrumentos internacionales, que es a través de los cuales es posible distinguir la garantía y ejercicio más pleno de este derecho. Al respecto Ponce Villacís refiere que tanto en los Convenios de la Organización Internacional del Trabajo (OIT), como en las declaraciones de la Organización de las Naciones Unidas (ONU) y de la Organización de Estados Americanos (OEA), se reconoce la existencia de los ordenamientos jurídicos ancestrales de los pueblos indígenas y el derecho que tienen dichos pueblos a que estos ordenamientos sean reconocidos y en consecuencia que tengan eficacia ${ }^{2}$.

En ese tenor, en 1957 fue posible concretar al interior de la OIT, parte de las preocupaciones y demandas indígenas. Éstas se plasmaron en el Convenio 107 sobre Poblaciones Indígenas y Tribales, adoptado el 27 de julio de ese año y luego ratificado por 27 países $^{3}$. A partir de este momento y principalmente en los años sesentas vamos a observar a sectores sociales de diversos países pronunciarse por el derecho al desarrollo, al progreso y a la autodeterminación. En esos círculos internacionales se inició también el debate sobre sí esos derechos (indígenas) reclamados no eran derechos

\footnotetext{
${ }^{1}$ ESTRADA MARTÍNEZ, R. (1997), Tradiciones y costumbres jurídicas en comunidades indígenas de México. México: Comisión Nacional de Derechos Humanos.

${ }^{2}$ PONCE VILLACÍS, A. (2006), "Los derechos de los pueblos indígenas", en MARTÍN, C. et. al., (Comp.): Derecho Internacional de los Derechos Humanos. México: Universidad Iberoamericana, A.C., Academia de Derechos Humanos y Derechos Internacional Humanitario, Washington College of Law, American University, Distribuciones Fontamara, S.A.

3 PEDROZA DE LA LlAVE, S.T. y GARCÍA HUANTE, O. (Comps.) (2003), Compilación de instrumentos internacionales de derechos humanos firmados y ratificados por México 1921-2003, t. 2. México: CNDH. .
} 
humanos, si estaban en una escala inferior a los derechos civiles y políticos, o si los derechos humanos atendían a los derechos del individuo y no de grupos $\mathrm{o}$ colectividades. En respuesta a esta discusión, Bailón y Brokmann, refieren que en 1989 surge el Convenio 169 sobre Pueblos Indígenas y Tribales en Países Independientes, con nuevos contenidos, para convertirse en el único instrumento internacional con carácter vinculatorio en relación con los derechos de los pueblos indígenas ${ }^{4}$.

El Convenio 169 de la OIT, en su artículo 8, punto 1 y 2, considera, como se observa a continuación, la existencia de un derecho consuetudinario.

1. Al aplicar la legislación nacional de los pueblos interesados deberán tomarse debidamente en consideración sus costumbres o su derecho consuetudinario.

2. Dichos pueblos deberán tener el derecho de conservar sus costumbres e instituciones propias, siempre que éstas no sean incompatibles con los derechos fundamentales definidos por el sistema jurídico nacional ni con los derechos humanos internacionalmente reconocidos. Siempre que sea necesario, deberán establecerse procedimientos para solucionar los conflictos que puedan surgir en la aplicación de este principio.

Pasaron cerca de tres décadas, para que en septiembre de 2007, la Asamblea General de la ONU diera un paso fundamental para el impulso del reconocimiento de los derechos de los pueblos indígenas, al adoptar la Declaración de la Naciones Unidas sobre los Derechos de los Pueblos Indígenas ${ }^{5}$. Al tenor de este auge de instrumentos internacionales para la protección de los pueblos indígenas, en la segunda sesión plenaria de la OEA en 2016, es aprobada la Declaración Americana sobre los Derechos de los Pueblos Indígenas (DADPI), que contiene un interesante apartado en el artículo XXII sobre derecho y jurisdicción indígena. Este precepto es de suma importancia tal y como se observa a continuación.

1. Los pueblos indígenas tienen derecho a promover, desarrollar y mantener sus estructuras institucionales y sus propias costumbres, espiritualidad, tradiciones, procedimientos, prácticas y, cuando existan, costumbres o sistemas jurídicos, de conformidad con las normas internacionales de derechos humanos.

2. El derecho y los sistemas jurídicos indígenas deben ser reconocidos y respetados por el orden jurídico nacional, regional e internacional ${ }^{6}$.

Finalmente, en lo que respecta a pueblos indígenas, la Corte Interamericana de Derechos Humanos (CrIDH), ha desplegado un extenso y variado manto de protección hacia los pueblos indígenas a través de sus resoluciones, manifestando que es indispensable que los Estados otorguen una protección efectiva que tome en cuenta sus

\footnotetext{
${ }^{4}$ BAILÓN CORRES, M.J. y BROKMANN HARO, C. (2015), Los pueblos indígenas de México y sus derechos: Una breve mirada, México: CNDH.

${ }^{5} \mathrm{Si}$ bien la Declaración no establece ningún derecho nuevo que no esté contemplado en otros instrumentos de derechos humanos de Naciones Unidas, es muy clara en cuanto a cómo se deben relacionar estos derechos con las condiciones específicas de los pueblos indígenas. La Declaración no solo es una muy especial esperada acta de resarcimiento para los pueblos indígenas, sino que también debe ser considerada como un mapa de acción para las políticas en derechos humanos que deben será adoptadas por los gobiernos, la sociedad civil y los propios pueblos indígenas si en verdad quieren que sus derechos sean garantizados, protegidos o promovidos. Al respecto véase STAVENHAGEN, R. (2008), "Los derechos de los pueblos indígenas: desafíos y problemas". San José: Revista del Instituto Interamericano de Derechos Humanos, Vol. 48. pp. 257-258.

${ }^{6}$ DECLARACIÓN AMERICANA SOBRE LOS DERECHOS DE LOS PUEBLOS INDÍGENAS. Aprobada el 14 de junio de 2016. [En línea] https://www.oas.org/es/sadye/documentos/res-2888-16es.pdf
} 
particularidades propias, sus características económicas y sociales, así como su situación de especial vulnerabilidad, su derecho consuetudinario, valores, usos y costumbres $[\ldots]^{7}$.

A partir de estas normas de carácter internacional, es posible advertir el reconocimiento expreso y la existencia de un derecho consuetudinario, fundamentalmente en la Declaración Americana y en las sentencias de la $\mathrm{CrIDH}$, sin embargo, en el Convenio 169 de la OIT se advierten dos limitantes a la eficacia de las normas consuetudinarias, que parten del término "incompatible", utilizado en su artículo 8, que bien puede entenderse a contrario sensu como la necesidad de estar siempre en sintonía con el derecho estatal y con el contenido de las normas emanadas de los tratados internacionales. En otras palabras -desde la perspectiva de la OIT- el derecho consuetudinario indígena no puede existir, si no está en armonía con el sistema jurídico nacional y con los derechos humanos. Esta es una disposición convencional compleja que genera más de un problema. En la praxis, no en pocas ocasiones, los usos y costumbres se alejan -en estricto sentido- de la norma positivada al momento de resolver sus controversias, principalmente de índole penal, ya que en ocasiones llegan a "conciliar" delitos graves como el robo con violencia y la violación, hecho que a primera vista, vulnera principios básicos tanto del sistema normativo nacional como de los instrumentos internacionales en materia de derechos humanos.

Independientemente de lo poco ortodoxo que pudieran resultar los mecanismos que emplean para la resolución de sus conflictos, resulta apresurado afirmar que los usos y costumbres de las comunidades del sur de México vulneran los derechos humanos reconocidos en la Constitución federal y en los instrumentos internacionales referidos, puesto que para estar del lado de los que opinan lo anterior, es pertinente previamente entender la cosmovisión indígena en la impartición de justicia, en la que se privilegian principios éticos como la verdad, la honestidad, el honor y el valor de la palabra. Tampoco podemos afirmar que el derecho consuetudinario está por debajo del sistema jurídico nacional, porque existe un reconocimiento constitucional para ambos, lo contrario sería discriminatorio. Stavenhagen, resuelve parcialmente este problema al opinar que de existir conflicto, en cuanto a derechos fundamentales, entre las normas domésticas y normas de derecho indígena, en aplicación del principio de favorabilidad, deberá aplicarse la norma que más favorezca la vigencia y protección del derecho en discusión ${ }^{8}$.

Lo cierto es que los pueblos indígenas han jugado de manera permanente un papel especial de la realidad social nacional. La independencia de México de 1821 y la Revolución Mexicana de 1910, no pueden entenderse sin la presencia de los pueblos indígenas. Junto con los campesinos, los indígenas constituyeron la base sobre la cual se

\footnotetext{
7 En el mismo sentido véase: Caso Comunidad Indígena Sawhoyamaxa Vs. Paraguay. Fondo, Reparaciones y Costas. Sentencia de 29 de marzo de 2006, párr. 83; Caso del Pueblo Saramaka. Vs. Surinam. Excepciones Preliminares, Fondo, Reparaciones y Costas. Sentencia de 28 de noviembre de 2007, párr.178; Caso Tiu Tojín Vs. Guatemala. Fondo Reparaciones y Costas. Sentencia de 26 de noviembre de 2008, párr. 96; Caso Pueblo Indígena Kichwa de Sarayaku Vs. Ecuador. Fondo y reparaciones. Sentencia de 27 de junio de 2012, párr. 264; Caso de los Pueblos Indígenas Kuna de Madungandí y Emberá de Bayano y sus Miembros Vs. Panamá. Excepciones Preliminares, Fondo, Reparaciones y Costas. Sentencia de 14 de octubre de 2014, párr. 167. CORTE INTERAMERICANA DE DERECHOS HUMANOS. Pueblos Indígenas y Tribales. Cuadernillo de jurisprudencia No. 11, pp.5-6. [En línea] http://www.corteidh.or.cr/sitios/libros/todos/docs/indigenas.pdf

8 STAVENHAGEN, R. (1990), "Derechos Consuetudinario Indígena en América Latina", en STAVENHAGEN R. Y ITURRALDE, D. (Comps.). Entre la Ley y la Costumbre. San José: Instituto Interamericano de Derechos Humanos.
} 
edificó el modelo de desarrollo económico posterior a la Revolución, proporcionando los productos agrícolas a bajo precio y la mano de obra barata que requirió el desarrollo industrializador de la Nación. En el calendario cívico, el discurso político y el imaginario colectivo que se creó en torno a las grandes gestas nacionales, el indígena aparece como un actor fundamental.

A pesar de esta permanente presencia histórica, los pueblos indígenas han ocupado el último lugar en materia de niveles de bienestar social, y son los menos atendidos por las políticas públicas. Estas limitantes no han significado un obstáculo para mantener por siglos un sistema jurídico tradicional, que hasta nuestros días continúa teniendo vigencia, y nos atrevemos a señalar, se ha constituido en la base para la creación de mecanismos alternativos de solución de conflictos, en boga actualmente en México y en otros países del mundo. Incluso en el gobierno anterior, se impulsaron en nuestro país interesantes iniciativas para crear una nueva Justicia Cotidiana ${ }^{9}$.

México es un país multicultural, y por ende, concentra infinidad de costumbres que dan origen a un sistema de justicia tradicional que puede presentar variantes de una región a otra, como es el caso de Chiapas. La nación incluye una muy rica diversidad de pueblos, cada uno de los cuales merecen respeto, y es digno de crecer y florecer ${ }^{10}$. Ocupa el octavo lugar mundial entre los países con mayor cantidad de pueblos indígenas. Conforme al Censo de Población y Vivienda 2010, el Instituto Nacional de Estadística y Geografía (INEGI) estima una población de 15.7 millones de indígenas en México. De éstos, 6.6 millones son hablantes de lengua indígena y 9.1 millones no hablan lengua indígena y 400 mil de los hablantes no se consideran indígenas. De las poco más de 192 mil localidades del país, en 34 mil 263, 40\% y más de sus habitantes es población indígena y, de ese total, casi 22 mil localidades tienen menos de 100 habitantes $^{11}$.

En esta misma fuente, puede consultarse que Chiapas registra 47 municipios indígenas, ubicados en las regiones de los Altos, Norte, Selva Lacandona y Frontera Sur, además de que posee una población indígena de 1 millón 511 mil habitantes ${ }^{12}$. Por otra parte, el artículo 7 de la Constitución local señala que Chiapas tiene una población pluricultural sustentada originalmente en sus pueblos indígenas. La Constitución reconoce y protege a los siguientes: Tseltal, Tsotsil, Chol, Zoque, Tojolabal, Mame, Kakchiquel, Lacandón, Mocho, Jacalteco, Chuj y Kanjobal.

El reconocimiento constitucional del derecho indígena en México es reciente. Si bien

\footnotetext{
${ }^{9}$ En razón de lo complejo que ha resultado para el Estado mexicano la implementación de mecanismos alternativos de solución, es necesario observar con mayor detenimiento los alcances de la Justicia Cotidiana, porque al final de cuentas no deja de ser un mecanismo legal para acceder a la justicia, independientemente que sea previo a la utilización de los mecanismos jurisdiccionales, como última instancia para la solución de conflictos. Esto implica que el Estado debe vigilar que el marco en que se propone la Justicia Cotidiana se cumpla con el propósito de remover los obstáculos que limitan el acceso a la justicia, favoreciendo a su práctica y desarrollo. En otras palabras, esta Justicia debe tener un alcance en calidad y eficacia, de tal forma que el propósito de resolver conflictos de naturaleza diversa a la penal, se desarrolle de manera justa, equitativa y expedita, terreno en el que hacen su aparición los derechos humanos y todo lo que su tutela implica. Al respecto véase GALINDO ALBORES, J.A. (2018), "Justicia Cotidiana y Derechos Humanos", en ARMENTA LÓPEZ, L.A. La Justicia en México. Temas selectos. México: Porrúa.

${ }^{10}$ LEÓN, O. (2004), Interculturalismo y justicia social. Autonomía e identidad cultural en la era de la globalización. México: Universidad Nacional Autónoma de México.

${ }^{11}$ SECRETARÍA DE GOBERNACIÓN, Programa Especial de los Pueblos Indígenas 2014-2018. [En línea] http://www.dof.gob.mx/nota_detalle.php?codigo=5343116\&fecha=30/04/2014

12 INEGI. Sistema de indicadores sobre la población indígena de México. Censos Generales de Población y Vivienda, México 1990 y 2000, II Conteo de Población y Vivienda México, 2005 y Censo de Población y Vivienda, México, 2010. [En línea] http://www.beta.inegi.org.mx/
} 
desde el derecho indiano ya se reconocían algunos derechos, estos solo estaban plasmados en el papel, pero carecían de eficacia en la praxis. Fue hasta 1992, mediante la reforma constitucional al artículo 4, en un primer y escueto párrafo, que se reconoció la composición pluricultural de la nación mexicana, sustentada originalmente en sus pueblos indígenas. En este precepto se contemplaron esencialmente los usos y costumbres de los pueblos y comunidades indígenas, sus formas específicas de organización social, así como el acceso a la administración de justicia. Disponía además que en los juicios y procedimientos agrarios en que aquellos fueran parte, se tomaran en cuenta sus prácticas y costumbres jurídicas. Es apenas a fines del siglo XX que inicia el reconocimiento de los derechos de los pueblos indígenas, hasta el momento inconcluso.

Los contenidos constitucionales de ese momento no eran suficientes para un movimiento indígena en ascenso. En enero de 1994, surge el Ejército Zapatista de Liberación Nacional (EZLN) en Chiapas, de esta manera el tema de los derechos indígenas se convierte en asunto nacional. Las negociaciones posteriores entre el Gobierno federal y el EZLN van a dar lugar a la creación de los llamados Acuerdos de San Andrés en 1996, que no tuvieron vigencia ni reconocimiento constitucional, sin embargo constituyen un documento histórico de gran valía para los pueblos indígenas de México. De esta manera, cerca de una década se debatió la pertinencia de darles un verdadero reconocimiento a los pueblos indígenas en la estructura legal mexicana. El mes de agosto de 2001, resulta significativo por la reforma constitucional a los artículo $1^{\circ}, 2^{\circ}, 4^{\circ} 18$ y 115 , que finalmente avanzaba en el reconocimiento de los pueblos indígenas.

Analizados esos momentos emblemáticos, podemos afirmar que el reconocimiento de un derecho indígena en México, encuentra sustento constitucional a partir de la referida reforma constitucional de 2001, en la fracción II del artículo $2^{\circ}$ que establece:

$[\ldots]$

II. Aplicar sus propios sistemas normativos en la regulación y solución de sus conflictos internos, sujetándose a los principios generales de esta Constitución, respetando las garantías individuales, los derechos humanos $\mathrm{y}$, de manera relevante, la dignidad e integridad de las mujeres. La ley establecerá los casos y procedimientos de validación por los jueces o tribunales correspondientes.

Al margen de las críticas de esta disposición constitucional, lo cierto es que el marco jurídico mexicano presenta a partir de las reformas de 2001, un avance en el reconocimiento a la diferencia cultural y el combate a la discriminación que parecía progresivo $^{13}$. Pero también, a pesar de nuevas leyes y el esfuerzo de instituciones especializadas, el avance reciente parece escaso y persiste en la sociedad el desconocimiento, la incomprensión y en ocasiones, la franca discriminación hacia los pueblos indígenas y a su cultura, usos y costumbres.

Aún con la ausencia de una ley general en materia indígena, en México existe un marco constitucional federal y leyes en la mayoría de entidades del país, que reconocen la posibilidad de que los pueblos indígenas puedan resolver sus conflictos internos a través de una justicia tradicional basada en sus usos y costumbres. Independientemente a su reconocimiento constitucional en el año 2001, es posible identificar que su sistema de justicia oral y casuística es una práctica añeja en las comunidades de Chiapas. Es decir, al momento de implementarse el sistema acusatorio adversarial penal y los

${ }^{13}$ CONSEJO NACIONAL PARA PREVENIR LA DISCRIMINACIÓN (2012), Encuesta Nacional sobre Discriminación en México. Resultados sobre diversidad cultural. México: CONAPRED. 
procedimiento orales a partir de 2008, para los pueblos indígenas, este mecanismo, con sus matices, era una práctica ya conocida para ellos, y aunque sus mecanismos jurídicos tradicionales también han evolucionado, es la forma como han resuelto sus conflictos durante siglos, sin acudir al sistema de justicia estatal. En suma han logrado crear un derecho no escrito, que busca siempre la verdad y la solución objetiva y pragmática de cada caso. De ahí, es posible afirmar que los pueblos y comunidades indígenas de Chiapas, gozan del derecho constitucional para establecer sus propios sistemas de justicia con pleno respeto a sus usos, costumbres y tradiciones.

No obstante este reconocimiento, al adentrarnos a la justicia indígena es posible identificar prácticas contrarias al sistema jurídico nacional y a los derechos humanos, como por ejemplo la conciliación en un caso de violación o robo con violencia. Para entender esta tensión natural de estos de los dos sistemas de justicia, es importante atender a la cosmovisión, organización y funcionamiento de la justicia indígena tradicional en las comunidades de Chiapas. Se trata de una investigación documental que también se soporta en entrevistas de campo a los principales operadores jurídicos y autoridades tradicionales, para crear un panorama objetivo de la forma en que se resuelven los conflictos por medio de los usos y costumbres, con la convicción genuina de buscar la verdad y la justicia.

\section{Justicia acusatoria adversarial, justicia indígena y cosmovisión.}

Por cuestión metodológica y porque consideramos pertinente conocer el estatus actual que guarda la justicia estatal y de esta manera contar con un margen de comparación con la justicia indígena que prevalece en las comunidades de Chiapas, en este apartado reproduzco de manera general los temas más destacados del actual sistema de justicia acusatorio adversarial, que vino a sustituir al sistema inquisitorio mixto, para posteriormente analizar la justicia y la cosmovisión desde la perspectiva indígena. Esta nueva justicia tiene cobertura nacional y por ende Chiapas está sujeto a este régimen.

La reforma constitucional de 2008, reconoció con énfasis el atraso e ineficacia del sistema penal inquisitorio para la vigencia de los derechos humanos que reconoce la constitución y sus garantías y procedimientos. Para implementar el nuevo sistema de justicia se modificaron en su contenido los artículos constitucionales 16.17, 18, 19, 20, $21,22,73,115$ y $123^{14}$.

Algunos de los aspectos más destacables de esta importante reforma al sistema de justicia penal en México son las siguientes: la creación de jueces de control para la solución inmediata de medidas cautelares y providencias precautorias; la implementación de mecanismos alternativos para la solución de controversias; el aseguramiento de la reparación del daño; la oralidad en las audiencias públicas, el juicio oral lo celebrará un juez que no haya conocido del caso previamente; la prisión preventiva oficiosa solo será ordenada por el juez en caso de delitos graves; la nulidad de la prueba obtenida con violación de derechos fundamentales; le pena deberá ser proporcional al delito que se sancione y el bien jurídico afectado, entre otros ${ }^{15}$. Como se puede observar la reforma de 2008 es de gran amplitud y complejidad en su tránsito hacia la consolidación de una nueva forma de hacer justicia en México.

\footnotetext{
${ }^{14}$ GOBIERNO FEDERAL (2008), Reformas constitucional de seguridad y justicia, México: Talleres Gráficos de México.

15 ARANDA HERNÁNDEZ, J.G. (2018), "Los grandes retos del sistema acusatorio adversarial", en ARMENTA LÓPEZ, L.A., La Justicia en México. Temas selectos. México: Porrúa.
} 
Ahora bien, como lo expresa el maestro de la escuela de Viena, Hans Kelsen, la justicia es una característica posible pero no necesaria de un orden social. Solo secundariamente, una virtud del hombre; pues un hombre es justo cuando su conducta concuerda con un orden social ${ }^{16}$. La justicia indígena resulta aún más complejo definir desde un punto de vista dogmático, derivado del sistema oral y casuístico que lo componen. Frente a esta complejidad, Gómez Valencia, plantea que, la justicia indígena en vez de estructurarse sobre un conjunto abstracto de derechos y una prelación por las sanciones punitivas como ocurre en el derecho estatal, se desarrolla y se dinamiza en torno a la fuerza integradora de la oralidad, la tradición, la identidad, la costumbre, el deber, el perdón, la persuasión, la alta valoración de lo colectivo y su interés por los derechos individuales occidentales ${ }^{17}$.

Por esa razón, sin ánimo conceptual, al hablar de Justicia Indígena, nos referimos a aquellas prácticas resultantes de las costumbres en las comunidades indígenas de Chiapas, a través de las cuales las autoridades legítimamente elegidas por sus miembros regulan diversos ámbitos de las actividades, relaciones sociales y todo tipo de conflicto que se desarrolla dentro de su comunidad.

En la cosmovisión de las comunidades indígenas de Chiapas, la armonía entre los miembros de la comunidad es elemento fundamental para la convivencia pacífica de la sociedad. Los conflictos que se suscitan al interior de sus comunidades rompen con este equilibrio, de manera que frente a una controversia las autoridades tradicionales buscan medidas para restablecer el equilibrio a través de una compensación o resarcimiento del daño además de servir de ejemplo para los demás miembros de la comunidad. El procedimiento y las resoluciones son acorde a la cosmovisión de las comunidades indígenas.

Para una mejor comprensión del funcionamiento de la justicia indígena en Chiapas, consideramos importante, atender dos interrogantes prioritarias: ¿Qué podemos entender por cosmovisión indígena? y ¿cómo interpretar esta cosmovisión, sin que se constituya en argumento relativista que justifique cualquier práctica social en las comunidades?

A la primera interrogante damos respuesta a través de una narrativa que pretende definir la cosmovisión indígena, atendiendo a los puntos de vista de los investigadores del tema. Para Hiebert, la cosmovisión incluye las suposiciones centrales, conceptos y premisas más o menos ampliamente compartidas por los miembros de una cultura o subcultura ${ }^{18}$. En ese contexto, la cosmovisión indígena nos asegura que lo que vemos, es cómo las cosas son realmente. La cosmovisión influye en la manera como vemos el mundo que gira a nuestro alrededor. No es lo que vemos, sino más bien con qué lo vemos. En ese sentido, una persona perteneciente a una cultura diversa a la nuestra, observa de manera diferente una misma realidad, aun en los niveles más fundamentales. Esto es lo que sucede con los usos y costumbres de los pueblos indígenas. Es necesario interiorizarse en su visión y pensamiento para poder entenderlos en su justa dimensión.

Por su parte, Ana Luisa Izquierdo refiere que la cosmovisión es el resultado de largos procesos históricos en los que la cultura va tomando identidad, creando un sistema taxonómico propio que dirige a sus participantes para verse a sí mismos y conceptuar el mundo natural y social en el que están inmersos, produciendo todo un pensamiento

\footnotetext{
${ }^{16}$ KELSEN, H. (2008), ¿Qué es la justicia?, México: Fontamara S. A.

${ }^{17}$ GÓMEZ VALENCIA, H. (2008), Justicias indígenas andinas. Popayán: Universidad del Cauca.

${ }^{18}$ HIEBERT, P. y HIEBERT MENESES, E. (1995), International Ministry: Playing Churches in Band, Tribal, Peasant an Urban Societies. Grand Rapids: Baker Book House.
} 
sobre el universo completo ${ }^{19}$. Lo anterior significa que la cosmovisión es un proceso lento, que surge por dos caminos: uno inconsciente, por las relaciones cotidianas de los hombres con otros hombres y con la naturaleza, es la creación cultural misma que va tomando forma y coherencia; y otro consciente, por la estructuración de ideologías que se imponen a un pueblo, generalmente desde los gobiernos o por conquistas ideológicas o bélicas.

Lo realmente importante es comprender que la cosmovisión se aprende del ambiente en el cual la persona crece como parte del proceso de la inculturación, es decir, empieza a formarse desde que nacemos, debido a que el recién nacido inicia el aprendizaje no solo del idioma y las costumbres, sino también las suposiciones, premisas y conceptos básicos de sus padres, familiares y comunidad. Por lo que la cosmovisión se aprende antes que el individuo tenga la capacidad de analizar y evaluar. Así, la mayor parte del tiempo las personas reciben y retienen las suposiciones de ésta, sin cuestionarlas. No se razonan, se asumen. A respecto, Díaz Gómez sostiene que una parte del comportamiento cultural del ser humano es consciente, por ejemplo, en cuanto a la lengua que usa, las relaciones con su grupo, las prácticas conocidas de todos, las fiestas y ceremonias comunes, etcétera. Pero hay otra parte que es normalmente subconsciente, por ejemplo, los valores que uno trae consigo, la manera de entender el universo, las creencias que uno tiene y que solo percibe que existen cuando encuentra a personas que tienen otra perspectiva de vida ${ }^{20}$.

La vida de los indígenas de las comunidades de Chiapas al igual que los de todo el país, gira alrededor de su comunidad. Es decir, del pueblo o comarca donde nacieron sus antepasados y en el que suelen buscar esposo o esposa. La comunidad es el espacio donde celebran sus fiestas y veneran a su santo patrono. También es el lugar donde la mayoría cultiva la tierra y consigue su sustento, aunque cada vez más personas se dediquen a otras actividades. Están dispuestos a defender sus tierras y el área que las rodea, pues es la base de su supervivencia como personas y de la comunidad misma.

En la comunidad deciden sus asuntos y rigen su vida cotidiana. En ese tenor, las comunidades son el centro de la identidad de los indígenas de Chiapas, que se definen, en primer lugar, como pertenecientes a su pueblo particular $\mathrm{y}$, por lo tanto, como diferentes a sus vecinos, aunque estos hablen su misma lengua y tengan una cultura muy parecida. Incluso, cuando una gran parte de los indígenas ha emigrado de sus pueblos de origen de manera temporal o permanente a lugares muy distantes, su comunidad es punto de referencia vital. Procuran volver en ocasión de las grandes fiestas, envían dinero para ayudar a sus familiares y también para contribuir a las fiestas y obras colectivas del pueblo. Muchos participan desde lejos en los asuntos y el gobierno de su comunidad.

En cuanto a la segunda interrogante, es posible encontrar la respuesta en la lucha de las comunidades indígenas por demostrar que sus costumbres han logrado sobrellevar elementos indiscutibles para la existencia de un verdadero pacto social en las comunidades de Chiapas. Ahí las autoridades tradicionales han buscado generar un espacio de convivencia pacífica con una organización propia, precedida de formas de pensamiento objetivamente delimitadas, producidas y aceptadas colectivamente, donde se acepta el conflicto como algo "natural" y por ende se privilegia la amigable

${ }^{19}$ IZQUIERDO, A. L. (2005), Términos básicos sobre derechos indígenas. Primera Edición, México: CNDH.

${ }^{20}$ DÍAZ GÓMEZ, F. (2001), Derechos humanos u derechos fundamentales de los pueblos indígenas", La Jornada, 31 de noviembre de 2001, p. 22. 
composición en lugar de medidas punitivas. Para ellos el perdón, la prevención y la compensación material del daño, son los elementos que restablecen las alianzas sociales. En ese sentido, la cosmovisión indígena respecto a la justicia cobra sentido, sin que ello signifique que podamos estar o no de acuerdo con las prácticas ancestrales para la definición de sus conflictos que pudieran configurar vulneraciones a los derechos humanos o al sistema de justicia estatal.

\section{Las autoridades responsables de impartir la justicia indígena.}

Es importante subrayar que la mayoría de municipios indígenas en Chiapas tienen el mismo sistema de organización y elección de sus autoridades o servidores públicos, excepcionalmente existen variaciones en algunos municipios. Cada municipio tiene aproximadamente de 20 a 500 comunidades o parajes, dependiendo de su extensión geográfica.

Cada paraje cuenta con una agencia rural integrada por el agente y subagente auxiliar municipal, e incluso algunos cuentan hasta con juez, subjuez y secretario, algunos con sus respectivos principales ${ }^{21}$, así como por un número de policías rurales que va en función del tamaño de la comunidad o paraje.

Todos los municipios indígenas cuentan con un agente auxiliar municipal, mejor conocido entre las comunidades como "agente del paraje o de la comunidad", a excepción del municipio de Tenejapa, donde no hay agente auxiliar municipal. Los agentes auxiliares duran en el cargo un año y es de carácter honorífico, pues es considerado como servicio social a la comunidad. La función principal del agente auxiliar municipal es resolver los problemas que se susciten en la comunidad y los conflictos entre particulares, además gestionan obras, organizan eventos y convocan a reuniones a los habitantes para recibir a las autoridades municipales, estatales o federales, entre otras actividades. Como excepción, el municipio de Mitontic desarrollan todas las funciones citadas, menos resolver controversias entre particulares, para ese caso los habitantes acuden al Juzgado de Paz y Conciliación Indígena municipal.

Los agentes auxiliares no atienden todos los días en la agencia municipal. Entre ellos acuerdan qué día les conviene servir, por lo tanto varía en los diferentes municipios. Como excepción, cuando se comete un delito grave como homicidio o violación, abandonan sus actividades cotidianas y acuden de manera inmediata a la agencia o al lugar de los hechos para dar fe. La elección de esta autoridad se efectúa cada año mediante asamblea pública, el agente rural en turno convoca a los habitantes para informar que está próximo a concluir el periodo de encargo y es momento de elegir, por lo que se proponen los nombres de quienes van a fungir como autoridades.

Para el municipio de San Juan Cancuc, antes de la asamblea pública el agente rural saliente y sus Principales, celebran una reunión privada donde se analiza a las personas que podrían ser las próximas autoridades de la agencia auxiliar municipal. Una vez acordado, se programa la asamblea con los habitantes de la comunidad, quienes de antemano saben que hay una propuesta por parte de las autoridades salientes y Principales. El día de la asamblea solicitan se dé a conocer los nombres para el nuevo agente y subagente auxiliar, por lo regular, los elegidos son ratificados en ese momento.

En ocasiones los habitantes mencionan otros nombres a lo acordado en la reunión

\footnotetext{
${ }^{21}$ Los Principales son ancianos, ex autoridades respetadas porque han tenido y tienen un modo honesto de vivir, reconocidos por la comunidad por ser justos y objetivos, son hombres con experiencia a quienes se les consultan los casos controvertidos o relevantes.
} 
previa, entonces se someten a votación y ha sucedido que gana una persona diferente. También es posible que los elegidos puedan excusarse del cargo en la asamblea y si la excusa procede, se busca a otra persona. Las razones para excusar una persona, son las siguientes: que no haya pasado mucho tiempo de haber ocupado dicho cargo; que fue nombrado agente auxiliar en otra comunidad al pertenecer a dos comunidades; por haber sido elegido con algún cargo en el municipio; por alguna enfermedad grave; que se ausente de la comunidad por una fuerza mayor durante ese año, entre otras. Lo importante es que estas excusas estén plenamente justificadas y que sean aceptadas por la asamblea.

Al tratarse de un servicio sin goce de sueldo, las personas no desean ser elegidas porque lo consideran una pérdida de tiempo que menoscaba su ingreso económico proveniente de su trabajo en el campo. Como la elección es por asamblea pública o por las propias autoridades y Principales ratificados en asamblea (el caso de San Juan Cancuc), negarse es motivo de sanción por parte de la comunidad, por lo que de cualquier forma los electos ejercerán la encomienda.

Es común que algunos habitantes no acudan a la asamblea porque creen que pueden ser electos. Situación inexcusable. La sanción para quien rehúsa asumir el cargo consiste en multa con cajas de refresco embotellado, cuya cantidad será proporcional al total de la población o al de los asistentes a la asamblea. En caso de negativa, será arrestado hasta que cumpla. Cuando una persona es elegida nuevamente para ocupar un cargo en el año consecutivo, el electo puede exponer que es injusto, ya que descuidará sus cosechas y la manutención de su familia, por lo cual su negativa es aceptada. Como se observa, en el sistema de justicia estatal estas conductas vulnerarían derechos fundamentales, entre otros, el derecho a no ser privado de la libertad personal si no es por causas y en las condiciones previstas en la ley y el derecho a no ser sometido a detención o encarcelamiento arbitrario (artículo 16 constitucional) y la libertad de profesión, industria, comercio o trabajo (artículo 5 constitucional).

El requisito indispensable para ser electo agente auxiliar, es haber ocupado con anterioridad varios cargos honoríficos, tener paciencia, capacidad de opinión, una vida ejemplar, pero sobre todo ser justo y objetivo en sus decisiones, ya que es la máxima autoridad en el paraje o comunidad. De igual forma, el subagente deberá ser honorable, distinguido y de buena reputación. Únicamente los hombres que cuentan con pareja ocupan este cargo en las comunidades, los solteros, estudiantes y mujeres están excluidos. En la justicia estatal esta conducta estaría vulnerando el derecho a la igualdad del varón y la mujer, que establece el artículo $4^{\circ}$ constitucional. Esta estructura es la regla general de las comunidades indígenas de Chiapas, aunque algunos municipios como Teopisca presentan pequeñas variantes.

En cuanto a la policía, normalmente son los jóvenes quienes ocupan estos cargos. Es una forma de adquirir experiencia para gobernar una comunidad, llegado el momento pueden ser agentes auxiliares si demuestran capacidad como policías.

Otra de las autoridades que resuelve problemas o delitos relacionados con la educación o la infraestructura educativa, es el Comité de Educación. Para su elección se ocupa el mismo método que el agente auxiliar municipal. Está integrado por un presidente y los vocales. Con una finalidad similar, existe la figura del Comité de Padres de Familia, que vela por las necesidades de la comunidad en materia educativa. La elección de los integrantes es la misma que las demás autoridades. Dicho Comité está conformado por un presidente, un secretario, un tesorero y vocales. También existe el Patronato de Obra, encargado de vigilar las construcciones que se estén realizando en la comunidad. 
En algunos municipios existe el Consejo de Ancianos, como en el municipio de San Juan Cancuc, integrado por personas que han ocupado cargos de fiesta del santo patrón San Juan y de San Lorenzo y cumplieron con los requisitos que por usos y costumbres se requiere. El Consejo tiene la facultad de opinar en conflictos o controversias relevantes o graves entre particulares o entre grupos, y a la vez funge como una segunda instancia en los conflictos. Sus integrantes no tienen un periodo por cumplir, son vitalicios.

Su tarea es orientar a las autoridades municipales o de los parajes, ya que son los encargados de preservar las costumbres o respetar los acuerdos que se hagan al interior de la comunidad. Los bajkawiltoetik tienen una función especial, además de ser los máximos líderes en el Consejo, rezan para que las autoridades municipales tengan la capacidad de solucionar los problemas y de gestión, pero sobre todo rezan para pedir a los dioses la vida, la salud y el bienestar de sus hermanos, así como para que la siembra crezca apropiada, de fruto y cosecha, incluso para que llueva.

El más importante representante de los municipios indígenas, es sin lugar a dudas el Presidente Municipal. Así, cuando hay un conflicto relevante que el juez no puede resolver, se invita al Presidente Municipal o al Ayuntamiento en su conjunto, para que escuchen, opinen y resuelvan el problema o delito de que se trate, junto con las demás autoridades del municipio.

\section{Los Juzgados de Paz y Conciliación Indígena en Chiapas.}

Las autoridades de Chiapas crearon en 1998, los Juzgados de Paz y Conciliación Indígena, mediante reformas constitucionales y a la Ley Orgánica del Poder Judicial de la entidad, con la finalidad de recoger las bondades de la administración de justicia tradicional de los pueblos indígenas y entrelazarlas con el sistema de justicia que consagra la Constitución federal ${ }^{22}$. De conformidad con el artículo 90 del vigente Código de Organización del Poder Judicial del Estado de Chiapas ${ }^{23}$, para ser Juez de Paz y Conciliación Indígena se requiere:

I. Tener cuando menos, veinticinco años de edad, al día de la designación;

II. Ser Licenciado en Derecho, con título legalmente expedido y registrado ante autoridad legalmente facultada para ello; este requisito podrá dispensarse por el Consejo de la Judicatura atendiendo las tradiciones culturales del municipio o la falta de abogados en el lugar;

III. No pertenecer al estado eclesiástico, ni ser ministro de algún culto religioso;

IV. Gozar de buena reputación y no haber sido condenado por delito doloso que amerite pena privativa de libertad mayor de un año, pero si se tratare de otro delito que lesione seriamente la fama del candidato, éste se considerará inhabilitado para el desempeño del cargo, cualquiera que haya sido la pena impuesta; y,

V. En los casos en que sea necesario, deberá acreditarse el dominio de la lengua indígena correspondiente a la región de que se trate.

\footnotetext{
${ }^{22}$ En el Periódico Oficial del Estado de Chiapas, número 020, y el 11 de mayo del mismo año, en el Periódico Oficial número 125, se publicaron diversas disposiciones al Código Penal y a los Códigos de Procedimientos Penales y Civiles para el Estado, que regulan el procedimiento con que se rigen dichos órganos administradores de justicia. [En línea] http://www.sgg.chiapas.gob.mx/periodicooficial/

${ }^{23}$ CÓDIGO DE ORGANIZACIÓN DEL PODER JUDICIAL DEL ESTADO DE CHIAPAS. [En línea] http://www.poderjudicialchiapas.gob.mx/forms/archivos/0db8codigo-de-organizacion-del-poder-judicialdel-estado-de-chiapas.pdf
} 
En cuanto al nombramiento, el artículo 91 del mismo ordenamiento señala que serán nombrados por el Consejo de la Judicatura tomando en consideración las propuestas de los Ayuntamientos respectivos, quienes deberán estar sujetos a un programa de capacitación en materia de medios alternativos de solución de controversias, aprobado por el Centro Estatal de Justicia Alternativa del Poder Judicial del Estado.

Como en muchos casos en México, la norma jurídica discrepa de los usos y costumbres. La realidad es la siguiente. El Juez de Paz y Conciliación Indígena es electo en asamblea general en el plebiscito cuando se elige al candidato a la presidencia municipal. Cabe destacar que en dicho plebiscito la mayoría de los municipios indígenas eligen a sus autoridades más importantes, y en otros, desde el presidente municipal hasta el último policía. En ciertos municipios, como Chanal, desde el síndico municipal hasta los policías solo duran en su cargo un año. Los requisitos para ser Juez de Paz y Conciliación Indígena son: haber prestado servicio a la comunidad, estar casado, tener paciencia, conocer de toda clase de problemas, contar con buena reputación, probidad, y sobre todo conocido como persona razonable, justa y objetiva.

El Secretario de Acuerdos del Juzgado de paz y Conciliación Indígena, es elegido y enviado por el Tribunal Superior de Justicia. En ese sentido, en entrevista con los jueces de paz y conciliación indígena, expresaron su preocupación y lamentan que el Secretario de Acuerdos, quien es abogado, no comprenda la lengua indígena del lugar, pues ello no ayuda en las resoluciones, ya que mientras en la Sala se atiende el conflicto o controversia entre las partes, el Secretario permanece en un cubículo, donde el juez al final únicamente le expone la manera como se resolvió el caso, para integrar el informe respectivo a la coordinación de Juzgados.

\section{El procedimiento en la justicia indígena}

Los delitos más comunes en las comunidades indígenas son el robo, problemas familiares, amenazas, daños en propiedad ajena, molestar a las mujeres, pleitos por estado de ebriedad, despojo, entre otros.

Para resolver estos delitos en la justicia indígena, se cuenta con el agente auxiliar municipal, máxima autoridad y encargado de conciliar o resolver las controversias que se susciten entre particulares o entre grupos de la comunidad. A continuación nos referiremos al procedimiento que se desarrolla ante esta autoridad.

El quejoso, víctima u ofendido, acude a la agencia auxiliar donde expone su caso. Una vez que el agente escucha el tipo de problema, interroga al quejoso. Si se desprende de este interrogatorio el nombre del causante del delito o infracción, en ese momento puede citar al infractor para que comparezca, en su defecto se le convoca para otro día, con el propósito de que escuche directamente la acusación que se señala en su contra.

Las autoridades municipales cuentan con el auxilio de los policías de la comunidad, quienes ayudan a notificar, citar o detener a los presuntos acusados, para que acudan a la audiencia. El agente auxiliar comisiona a los policías para que "inviten" al acusado o acusados a que se presenten en la agencia. Es una costumbre en las comunidades que el infractor acuda voluntariamente a escuchar de qué se le acusa, lo cual no significa que acepte su culpabilidad. Los policías no pueden utilizar la fuerza física cuando van por una persona.

Cuando el delincuente o acusado no acude voluntariamente al llamado del agente auxiliar, los policías pueden detenerlo y llevarlo ante la autoridad correspondiente. No obstante, debe destacarse, que los policías no tienen permitido meterse a la casa de los 
presuntos culpables ni tampoco golpearlos. Es decir, la integridad personal es respetada, entendida ésta según Reyes Vanegas, como el conjunto de condiciones que permiten que una persona pueda gozar de su vida, con la plenitud de las funciones orgánicas y psíquicas, que le son propias $^{24}$. Esta garantía debe ser apreciada por la justicia estatal, donde se encuentran registrados incontables hechos que vulneran el derecho humano a la integridad personal, entre otros, cuando de una investigación penal se trata.

Presente el acusado, el agente auxiliar solicita a la víctima que exponga su caso. El acusado solo escucha, posteriormente hace uso de la palabra para defenderse. De no aceptar los cargos o contar con testigos como prueba de su dicho, entonces se requiere la presencia de éstos para esclarecer los hechos. Si los testigos están presentes son atendidos en la misma audiencia, si no lo están, se fija otra fecha para que acudan los testigos de ambas partes y presenten pruebas, que incluso, pueden ser de carácter documental.

Después de escuchar a ambas partes, el agente auxiliar procura mediar para llegar a un acuerdo. En caso de no lograrlo, procede a emitir una resolución de manera verbal en ese momento y da la razón a quien la tenga. Ese acto simplista no podría funcionar de no ser porque se privilegia la verdad, se le da un valor especial a la justicia, y particularmente el empeño de la palabra y el honor, significan todo en las comunidades indígenas.

Nos detenemos para enfatizar la importancia que reviste el honor en el entendimiento y comprensión indígena, cuyo significado tiene una validez superior, porque para ellos está íntimamente ligado a la dignidad de la persona, derecho supremo de los derechos humanos, es también un elemento valorativo que genera una ventaja importante para la resolución de conflictos comunitarios y en la capacidad de restaurar la paz social. Esta visión es por demás interesante si transcribimos las palabras de Pérez Fuentes, quien define al honor como el conjunto de condiciones necesarias para que se mantenga vivo ese carácter decoroso en la persona a través de un conjunto de normas que protegen la dignidad de los seres humanos de la que emanan facultades y deberes ${ }^{25}$. Y aunque el derecho al honor no se encuentra reconocido en la Constitución mexicana, sí está reconocido en los instrumentos internacionales de derechos humanos de los que México forma parte, en los términos del artículo 133 de la Constitución ${ }^{26}$.

Resuelto quién es el responsable del delito, da inicio la negociación del pago de la reparación del daño. La víctima pide una cantidad de dinero por el daño sufrido y el responsable negocia dicha cantidad. En caso de no llegar a un acuerdo, el agente auxiliar determina la cantidad media de lo que cada parte ofrece. Si el responsable acepta pagar la cantidad, y en ese momento no la tiene, solicita unos días para pagar. Cuando un infractor se niega a pagar, va a la cárcel para que reflexione y más tarde o al otro día se retoma la audiencia para el pago del daño.

En el supuesto extremo de que definitivamente se niegue a pagar y la cantidad de dinero es elevada o el asunto es relevante, el agente auxiliar manda a los policías para que acompañen al responsable a realizar un préstamo, o bien se le venden sus terrenos o animales, además de pagar por aparte una multa con la autoridad. En este supuesto, nuevamente observamos que llevado a la justicia estatal no sería posible atentar contra

\footnotetext{
${ }^{24}$ REYES VENEGAS, A. (2001), Derecho a la integridad. Bogotá: Defensoría del Pueblo, p. 17.

${ }^{25}$ PÉREZ FUENTES, G. M. (2013), "Derecho al honor", en ISLAS COLÍN, A. y SÁNCHEZ CANO, J.E., Derechos humanos frente a una sociedad globalizada. México: Porrúa.

${ }^{26}$ CARBOnELL, M. (2009), Los derechos fundamentales en México, $3^{a}$. Ed. México: Porrúa-CNDHUNAM.
} 
el derecho a la propiedad (para algunos, denominado el derecho humano al goce y disfrute de las cosas) ya que al hablar de éste se reconoce, como señala Ramírez y Pallares, la existencia del derecho de poseer pública y pacíficamente ciertos bienes sobre los que se ejerce dominio y a la protección contra despojos arbitrarios ${ }^{27}$. Esto es así, porque de acuerdo al constitucionalismo mexicano el derecho a la propiedad solo puede ser limitado por causa de utilidad pública a cambio de justa indemnización.

Muchas veces no existe una víctima como tal, sino que alguna autoridad o cualquier persona de la comunidad pueden denunciar, de tal manera que el agente auxiliar atiende dicha denuncia y determina la existencia o no de un delito, para finalmente aplicar la sanción correspondiente cuando se trata de un ilícito. Si la autoridad comprueba que la acusación es falsa, se le aplica al responsable una sanción que consiste en horas de cárcel o multa consistente en la entrega de cajas de refresco, que se destina para la autoridad.

Otra de las actividades relevantes en este proceso de justicia indígena, es que las autoridades pueden investigar y acudir el lugar de los hechos, para dar fe de personas o cosas. El agente auxiliar puede utilizar como medida de apremio la cárcel por horas o máximo un día, dependiendo de la gravedad de los hechos o de alguna conducta no aceptada por la comunidad o autoridad, para que el infractor reflexione sobre su acción. Estas hipótesis son las siguientes:

a. Ser detenido al momento de estar cometiendo el delito.

b. No comparecer a una audiencia a la que fue citado por el agente, y es detenido por la policía para presentarlo a la audiencia.

c. Negarse a pagar la reparación del daño.

d. No pagar la multa.

e. Negativa para llegar a un acuerdo.

f. Mentir a la autoridad (falsa declaración ante la autoridad).

g. Faltar el respeto al agente rural o a otra autoridad.

h. Insulta a los presentes en la audiencia.

La multa tiene dos utilidades prácticas en la justicia indígena: como reparación del daño a la víctima y como pago ante la autoridad por concepto de sanción pecuniaria. Por lo tanto, el responsable de un delito paga una multa, que es para la persona que sufrió algún daño o lesión, y una multa a la autoridad, que puede consistir en cajas de refresco, o bien, en dinero calculado por el precio de las cajas de refresco.

De no resolverse la controversia a través del agente auxiliar, las partes acuden con el Juez municipal, o ante el Juez de Paz y Conciliación Indígena, por lo que el agente auxiliar comunica al Juez de Paz y Conciliación Indígena que las partes piden acudir al Juzgado municipal. Normalmente los asuntos no llegan al Ministerio Público (autoridad estatal), se resuelven en la comunidad o en el paraje.

Es pertinente acotar, que el Código de Procedimientos Civiles, el Código de Procedimientos Penales y el Código de Organización del Poder Judicial del Estado, dotan de facultades a los Juzgados de Paz y de Conciliación Indígena para sustanciar y resolver los conflictos que se susciten entre los miembros de las comunidades indígenas del estado, mediante la aplicación de sus usos, costumbres y tradiciones, salvaguardando los derechos humanos que establece la Constitución Política de los Estados Unidos Mexicanos.

\footnotetext{
${ }^{27}$ RAMÍREZ GARCÍA, S.H. y PALLARES YABUR, P.J. (2011), Derechos Humanos. México: Oxford.
} 
Los procedimientos ante esta instancia se desarrollan en la Sala de Audiencia de estos Juzgados cuyo cupo es de aproximadamente de 30 personas, con bancas de madera en ambas partes y un espacio al frente donde está el Juez y su Secretario o el Subjuez. Al lado se colocan las autoridades tradicionales. Este tribunal cobra vigencia en el contenido del artículo 87 del Código de Organización del Poder Judicial del Estado de Chiapas, al establecer que, en los Juzgados de Paz y Conciliación Indígena, las controversias serán tramitadas y resueltas por el Juez, quien previamente deberá oír a las autoridades tradicionales del lugar.

La competencia en materia penal la regula el capítulo II, artículo 211, apartado b) del Código de Organización del Poder Judicial del Estado de Chiapas, que establece lo siguiente:

II. Intervenir en el proceso conciliatorio previo a la denuncia o querella, tratándose de delitos que se persigan a petición de la parte ofendida, y de aquellos en que los interesados decidan someterse a la conciliación, siempre y cuando no se trate de los que la ley califique como graves o se afecte sensiblemente a la sociedad.

El supuesto de esta norma tampoco se cumple, ya que las autoridades tradicionales, el Presidente Municipal y el cuerpo del Ayuntamiento, únicamente se presentan cuando el problema es de suma relevancia. En la práctica, en los municipios indígenas el Juez de Paz y Conciliación Indígena resuelve todo tipo de problemas o controversias que se susciten dentro del municipio, mediante la razón, la justicia y las costumbres de la comunidad. Soluciona los problemas no resueltos en los parajes por los agentes auxiliares, su función principal es la conciliación. En la audiencia aconseja y exhorta a las partes, si se trata de jóvenes los involucrados, les explica las consecuencias que puede traerles para su vida futura.

La mayoría de los casos que atienden son problemas familiares. El procedimiento es el siguiente. El quejoso llega al juzgado y expone al juez su caso, si ya fue atendido en algún paraje le hace de su conocimiento al juez, quien luego manda a citar a la parte acusada. De peligrar la vida o integridad física, resuelven de inmediato o toman las medidas pertinentes, caso contrario, el juez fija una fecha y manda a citar al presunto responsable, a los testigos, autoridades o personas que sea necesaria su presencia para el esclarecimiento de los hechos.

El Juez de Paz y Conciliación funge también como tribunal de alzada o de segunda instancia. Conoce y resuelve cuando una de las partes no estuvo conforme con la resolución de los agentes auxiliares o no se llega a una conciliación. También si el acusado o la víctima no quieren que se resuelva ante el agente, o bien, porque el agente esté favoreciendo a una de las partes o pide una cantidad elevada para la reparación del daño. El Juez también cita a la audiencia al agente auxiliar que haya conocido del caso en primera instancia, con la finalidad de que explique el sentido de su resolución o cómo pretendía resolver, también para que ninguna de las dos partes cambie su dicho.

El día de la audiencia, el juez explica el motivo de la reunión, cede la palabra a la víctima para que formule sus acusaciones y pide al presunto responsable que preste atención a las imputaciones. Una vez que termina de hablar la víctima, toca el turno a los testigos. El juez pregunta al acusado qué opina o alega con relación a lo ha manifestado por el quejoso y testigos concediéndole el uso de la palabra. También se escucha a los familiares y demás acompañantes. A todos se les exhorta sobre el respeto que debe prevalecer en la comunidad. Si los dos tienen la culpa, la multa es 
para ambos y se mide en determinada cantidad de cajas de refresco, según la gravedad del problema.

Cuando es evidente la responsabilidad del acusado, la víctima y su familia analizan la sanción que van a solicitar. Normalmente piden una cantidad económica como reparación del daño. El juez sensibiliza y orienta al acusado al comentarle que si lo llevan a la ciudad, los gastos se incrementarán y la familia sufrirá las consecuencias de un proceso largo, que implica viajar constantemente, con la posibilidad de que permanezca años en la cárcel. Muchas veces el acusado consulta a un abogado para conocer la magnitud del delito y la conveniencia de llegar a un acuerdo.

Esas razones influyen para que el Juez procure la conciliación de las partes. En ocasiones la víctima pide una multa desproporcionada y eso dificulta que se llegue a un acuerdo con el responsable. El juez apercibe a la víctima para que la reparación del daño exigida sea equitativa. Es entonces cuando las partes suelen llegar a un acuerdo justo, entre el daño causado y su reparación.

Destaca que es la víctima u ofendido quien pide la reparación del daño, nunca el Juez, quien se ciñe a sancionar con multa cuando los dos son responsables. Cuando no es así, la víctima u ofendido solicita la reparación del daño y solamente en caso de que las partes no se pongan de acuerdo, el Juez interviene para fijar un término medio de la cantidad solicitada. Así se resuelve el problema de la reparación del daño a través del derecho consuetudinario, en la mayoría de comunidades indígenas de Chiapas.

En la práctica, los Jueces de Paz y Conciliación Indígena conocen todo tipo de problemas y delitos, incluso delitos graves, como robo con violencia o violación, siempre y cuando la víctima esté de acuerdo, a excepción del homicidio con alevosía, premeditación o ventaja. En este contexto, la información que el Juez envía a la Coordinación de Juzgados de Paz y Conciliación Indígena no es exacta, pues como hemos referido, esta autoridad conoce de todo tipo de controversias. Así, el Juez indígena no deja constancia ni reporta algunos casos por miedo de ser sancionado al resolver controversias fuera de su competencia.

La justificación del Juez para resolver delitos graves, es que en la ciudad el procedimiento es largo y costoso para ambas partes. Se pone en una balanza los años de cárcel que puede pasar el acusado y la falta de reparación del daño a la víctima. Una decisión poco ortodoxa para la justicia estatal, que puede llegar a violentar derechos humanos relacionados con el debido proceso, pero válida en el derecho indígena.

Entre las ventajas que podemos atribuirle a este sistema de justicia indígena, es que se cumplen los principios de concentración, contradicción, oralidad e inmediatez. Es por mucho, más expedito que el nuevo sistema acusatorio implementado a partir del año 2008 en nuestro país, pues garantiza y privilegia la reparación del daño. La víctima u ofendido junto con sus familiares o acompañantes analizan el monto que se pedirá al acusado. Éste último ofrece, y así negocian ambas partes hasta llegar a un acuerdo. En el caso de que después de escuchar, conciliar o mediar y resolver, alguna de las partes no esté de acuerdo, se les deja a salvo sus derechos para que acudan al Ministerio Público o a la instancia que consideren idónea. 


\section{La oralidad y la casuística, elementos que sustentan el sistema consuetudinario de justicia indígena.}

El sistema de justicia de las comunidades indígenas de Chiapas está basado en la oralidad y resolución casuística de los casos, es decir, en cada caso particular y en la razón para resolver los problemas. No existe sistematización alguna de este derecho, ni elaboran normas generales escritas que deban aplicarse siempre. Estos elementos son importantes si consideramos que algunos estudiosos de la materia indígena, proponen codificar o establecer por escrito sus normas y leyes tradicionales, lo cual desde nuestro punto de vita, generaría una rigidez normativa, similar a la del sistema legal nacional, ya que el derecho indígena está caracterizado por su flexibilidad y capacidad para adaptarse a la dinámica social.

Este sistema de justicia indígena permite a las autoridades tradicionales resolver diferendos y conflictos entre los integrantes de un núcleo social, utilizando recursos, normas, procedimientos y sanciones distintos al sistema de justicia nacional. Los indígenas y las autoridades tradicionales identifican cualquier transgresión a la ley como un peligro para la comunidad y para el equilibrio del cosmos mismo. Por esa razón, en el mundo indígena suele ser más importante reparar la falta que castigar al culpable.

Resulta relevante la forma expedita como se resuelven las controversias en esta clase de justicia. Sus elementos de oralidad y casuística no dan lugar a ningún tipo de rezago judicial como sucede en la justicia estatal. El trabajo consiste en conciliar a las partes en disputa para procurar que lleguen a un acuerdo. Esa idea que se tiene del acuerdo y el consenso, genera resultados prácticos y eficaces en la mayoría de casos.

En la justicia estatal, el proceso legal consagrado como derecho fundamental en los artículos 14 y 16 constitucionales, consiste básicamente en que una autoridad no puede afectar a un particular en su persona o en sus derechos. Al respecto Fix Zamudio se refiere al debido proceso legal, como el conjunto de condiciones y requisitos de carácter jurídico y procesal que son necesarios para poder afectar legalmente los derechos de los gobernados ${ }^{28}$. Este acto de afectación -en principiodebe estar precedido de un procedimiento en el que se escuche previamente al afectado en defensa de sus derechos, dándole a conocer los elementos del caso en forma completa, clara, abierta y una oportunidad razonable, según las circunstancias del caso, para probar y alegar lo que a su derecho convenga. El acto de afectación en sí mismo debe constar por escrito y emanar de la autoridad legalmente facultada para dictarlo. En dicho acto o mandamiento debe hacerse constar los preceptos legales que funden materialmente la afectación al individuo, así como los hechos que hagan que el caso actualice las hipótesis normativas y den lugar a la aplicación de los preceptos aplicados.

En la cosmovisión indígena, los elementos referidos que son base del debido proceso, se respetan y se cumplen, en razón de que el procedimiento del sistema de justicia indígena está regido por reglas y principios preestablecidos por las costumbres, a diferencia del debido proceso del sistema positivo nacional. El mandamiento o la orden de autoridad que debe constar por escrito conjuntamente con los preceptos legales aplicables al caso, no se viola, puesto que la justicia indígena tiene la característica - por usos y costumbres- de ser netamente oral.

\footnotetext{
${ }^{28}$ FIX-ZAMUDIO, H. (1987), Diccionario Jurídico Mexicano. México: Porrúa-UNAM, pp. 820-822.
} 
En cuanto a la fundamentación, ésta no existe dentro de este sistema indígena, no obstante, todo acto que afecta la esfera jurídica de alguna persona está sustentado básicamente en los valores y principios que rigen las costumbres de cada comunidad. Además, la justicia indígena tiene notas fundamentales que corresponden a un proceso penal de corte acusatorio y adversarial, tan de moda en nuestros días, al privilegiar la oralidad, la contradicción y la conciliación como un mecanismo de justicia que ayuda a restaurar el tejido social y la armonía en la comunidad a través de procesos de amigable composición.

Por ende, las audiencias son orales, participan el juez, el acusado, la víctima y los integrantes de la familia de ambas partes. Sin tanto "papeleo", se privilegia la conciliación como mecanismo para evitar males mayores para la comunidad, parecido a lo que actualmente se conoce en México con el nombre de justicia restaurativa. Sumándole atributos, en los juzgados indígenas no hay rezago judicial, ni tampoco incertidumbre jurídica en la resolución.

Como colofón, podemos opinar que la justicia indígena tiene sus bondades en la resolución de conflictos tal y como se ha sostenido a lo largo de este trabajo, pero también complejos problemas como cualquier sistema que intente impartir justicia en el mundo. La impartición de justicia en las comunidades indígenas de Chiapas, también genera conductas irregulares, es decir, resoluciones imparciales, deficiencias, multas excesivas y detenciones prolongadas, injustas, inequitativas y soluciones amigables de delitos graves, que pueden llegar a conculcar los derechos humanos de cualquiera de los involucrados. Sostener lo contrario puede significar un error, sin embargo, no debemos olvidar que cualquier arreglo o solución parte de la idea primigenia de la manifestación libre de la voluntad de las partes. Pese a todo ello, es un sistema de justicia que funciona en el contexto de la cosmovisión indígena.

\section{Conclusiones.}

No soslayamos los desafíos que enfrenta actualmente la justicia indígena en las comunidades de Chiapas - entidad del sur de México - por alcanzar su reconocimiento pleno. En ese tenor, el presente trabajo ha expuesto la organización y procedimiento de todo un sistema oral de normas no codificadas, mediante las cuales estas comunidades resuelven sus diferencias y conflictos personales, con una visión particular de la justicia, la verdad y la convivencia pacífica.

La justicia indígena en esta parte del territorio nacional, cuenta con una cultura propia acerca de la legalidad y la justicia. Al interior de la comunidad las normas de convivencia social y las sanciones por su infracción, son conocidas por todos. Además, las autoridades encargadas de impartir justicia en las comunidades de Chiapas, gozan de amplio reconocimiento de una sociedad que las elige mediante procedimientos democráticos, acto que las arropa de legitimidad si consideramos que para desempeñar esta clase de cargo, la persona debe contar con indiscutibles méritos éticos y morales. En síntesis, garantiza en buena medida, el respeto a la dignidad de las personas, privilegia la conciliación y de manera sobresaliente resuelve con inmediatez la reparación del daño, además de que el procedimiento se rige bajo los principios de oralidad, contradicción, publicidad, inmediatez y sin formalismos burocráticos.

La justicia indígena tradicional parece ser tan inevitable como necesaria y puede llegar a ser más efectiva que conflictiva, si consideramos que las autoridades tradicionales cumplen con una misión pacificadora de la comunidad al resolver 
internamente problemas que en el ámbito de la justicia estatal generaría -posiblemente- un escenario de conflictos incomprensibles y complejo.

Es cierto que existen tensiones entre la justicia indígena y el derecho positivo nacional, fundamentalmente cuando se trata de resolver delitos considerados como graves, tales como robo con violencia y violación, donde el acuerdo de voluntades ungido por los usos y costumbres, genera la pauta para concebir que se están vulnerando los derechos humanos de las víctimas; pero también es cierto, que en la justicia indígena se trabaja en la búsqueda de la verdad y para solucionar conflictos de la manera más amigable posible, buscando siempre el acuerdo voluntario de las partes, que puede llegar a extremos poco ortodoxos, pero no por ello menos eficaces. Esta reflexión abre la puerta a una nueva e interesante interrogante, que no forma parte de esta investigación, pero que seguramente será merecedora de investigaciones posteriores: ¿Es posible limitar los derechos humanos por los usos y costumbres, cuando las partes involucradas en un conflicto así lo pactan?

En el país se desarrollan nuevos sistemas jurídicos que han regresado a la oralidad, como herramienta legal para encontrar la verdad y la justicia social, tal y como se practica desde siglos en las comunidades indígenas de Chiapas. Esperamos que la idea de sensibilizarnos respecto al papel pacificador que juega la justicia indígena y sus mecanismos para la solución de conflictos, encuentre en este trabajo un campo fértil para su estudio y discusión.

\section{Bibliografía.}

-ARANDA HERNÁNDEZ, J.G. (2018), "Los grandes retos del sistema acusatorio adversarial”, en ARMENTA LÓPEZ, L.A., La justicia en México. Temas selectos. México: Porrúa. pp. 30-32.

-BAILÓN CORRES, M.J. y BROKMANN HARO, C. (2015), Los pueblos indígenas de México y sus derechos: Una breve mirada, México: CNDH,

-CARBONELL, M. (2009), Los derechos fundamentales en México, $3^{\mathrm{a}}$. Ed. México: Porrúa-CNDH-UNAM.

-CONSEJO NACIONAL PARA PREVENIR LA DISCRIMINACIÓN (2012), Encuesta Nacional sobre Discriminación en México. Resultados sobre diversidad cultural. México: CONAPRED.

-DÍAZ GÓMEZ, F. (2001), "Derechos humanos u derechos fundamentales de los pueblos indígenas", La Jornada, 31 de noviembre de 2001, p. 22.

-ESTRADA MARTÍNEZ, R. (1997), Tradiciones y costumbres jurídicas en comunidades indígenas de México. México: Comisión Nacional de Derechos Humanos.

-FIX-ZAMUDIO, H. (1987), Diccionario Jurídico Mexicano. México: Porrúa-UNAM, pp. 820-822.

-GALINDO ALBORES, J.A. (2018), "Justicia Cotidiana y Derechos Humanos", en ARMENTA LÓPEZ, L. A. La Justicia en México. Temas selectos. México: Porrúa. 
-GOBIERNO FEDERAL (2008), Reformas constitucional de seguridad y justicia, México: Talleres Gráficos de México, p. 1.

-GÓMEZ VALENCIA, H. (2008), Justicias indígenas andinas. Popayán: Universidad del Cauca.

-HIEBERT, P. y HIEBERT MENESES, E. (1995), International Ministry: Playing Churches in Band, Tribal, Peasant an Urban Societies. Grand Rapids: Baker Book House.

-IZQUIERDO, A.L. (2005), Términos básicos sobre derechos indígenas. Primera Edición, México: CNDH.

-KELSEN, H. (2008), ¿Qué es la justicia?, México: Fontamara S. A.

-LENKERSDORF, C. (1998), Cosmovisiones, México: UNAM, Centro de Investigaciones Interdisciplinarias en Ciencias y Humanidades.

-LEÓN, O. (2004), Interculturalismo y justicia social. Autonomía e identidad cultural en la era de la globalización. México: Universidad Nacional Autónoma de México, p. 9.

-PEDROZA DE LA LLAVE, S.T. y GARCÍA HUANTE, O. (Comps.) (2003). Compilación de instrumentos internacionales de derechos humanos firmados $y$ ratificados por México 1921-2003, t. 2. México: CNDH.

-PÉREZ FUENTES, G.M. (2013). "Derecho al honor”, en ISLAS COLÍN, A. y SÁNCHEZ CANO, J.E., Derechos humanos frente a una sociedad globalizada. México: Porrúa.

-PONCE VILLACÍS, A. (2006), "Los derechos de los pueblos indígenas", en MARTÍN, C. et. al., (Comp.): Derecho Internacional de los Derechos Humanos. México: Universidad Iberoamericana, A.C., Academia de Derechos Humanos Y Derechos Internacional Humanitario, Washington College of Law, American University, Distribuciones Fontamara, S.A.

-STAVENHAGEN, R. (1990), "Derechos Consuetudinario Indígena en América Látina", en STAVENHAGEN R. e ITURRALDE, D. (Comps.), Entre la Ley y la Costumbre. San José: Instituto Interamericano de Derechos Humanos.

-STAVENHAGEN, R. (2008), "Los derechos de los pueblos indígenas: desafíos y problemas". San José: Revista del Instituto Interamericano de Derechos Humanos, Vol. 48. pp. 257-258.

-RAMÍREZ GARCÍA, S.H. Y PALLARES YABUR, P.J. (2011), Derechos Humanos. México: Oxford.

-REYES VENEGAS, A. (2001), Derecho a la integridad. Bogotá: Defensoría del Pueblo. p. 17. 


\section{Recursos en Red}

-CÓDIGO DE ORGANIZACIÓN DEL PODER JUDICIAL DEL ESTADO DE CHIAPAS. [En línea]

http://www.poderjudicialchiapas.gob.mx/forms/archivos/0db8codigo-de-organizaciondel-poder-judicial-del-estado-de-chiapas.pdf

-CORTE INTERAMERICANA DE DERECHOS HUMANOS. Pueblos Indígenas y Tribales. Cuadernillo de jurisprudencia No.11, pp. 5-6. [En línea] http://www.corteidh.or. cr/sitios/libros/todos/docs/indigenas.pdf

DECLARACIÓN AMERICANA SOBRE LOS DERECHOS DE LOS PUEBLOS INDÍGENAS. Aprobada el 14 de junio de 2016. [En línea] https://www.oas.org/es/sadye/documentos/res-2888-16-es.pdf

-INEGI. SISTEMA DE INDICADORES SOBRE LA POBLACIÓN INDÍGENA DE MÉXICO. Censos Generales de Población y Vivienda, México 1990 y 2000, II Conteo de Población y Vivienda México, 2005 y Censo de Población y Vivienda, México, 2010. [En línea] http://www.beta.inegi.org.mx/

-PERIÓDICO OFICIAL DEL ESTADO. [En línea]

http://www.sgg.chiapas.gob.mx/periodicooficial/

-SECRETARÍA DE GOBERNACIÓN, Programa Especial de los Pueblos Indígenas 2014-2018. [En línea]

http://www.dof.gob.mx/nota_detalle.php?codigo=5343116\&fecha=30/04/2014 